\title{
Insulinoma-Associated Protein 1 (INSM1) as a Novel Immunohistochemical Marker for Neuroendocrine Neoplasms
}

\author{
DALIA ABD EL-KAREEM, M.D.; HEBA A. IBRAHIM, M.D. and SOMIA A.M. SOLIMAN, M.D. \\ The Department of Pathology, Faculty of Medicine, Cairo University
}

\begin{abstract}
Background: Diagnosis of neuroendocrine differentiation is important for tumor classification in different body systems. Confirmation of neuroendocrine differentiation, sometimes require immunohistochemistry (IHC) where morphology is not enough. Conventional immunohistochemical Neuroendocrine markers are used as complementary tools for the diagnosis of NETs, however sometimes all of them are negative and the diagnosis could still be a challenge. In this regard, different studies were performed on insulinoma-associated protein 1 (INSM1) as a novel and helpful immunohistochemical marker for neuroendocrine neoplasms with higher sensitivity and specificity.
\end{abstract}

Aim of Study: This study aims at proving the significance of INSM1 as a novel NE marker and to prove its superiority to other conventional NE markers.

Material and Methods: The current study is carried out on 102 cases of different neuroendocrine tumors paraffin blocks that were collected from Pathology Department, Faculty of Medicine, Cairo University \& private labs between January 2016 \& January 2020. Formalin fixed paraffin-embedded sections of 4 microns thickness were cut on positively charged glass slides and immunostained using INSM1 mouse monoclonal antibody. Another neuroendocrine marker (synaptophysin and/or chromogranin A) was done for confirmation of diagnosis \& $\mathrm{Ki}-67$ for grading.

Results: Positive nuclear expression of INSM1 was detected in 90 cases $(88 \%) .41 .2 \%$ score $1,40.2 \%$ score $2,6.9 \%$ score 3. Negative expression was detected in the remaining 12 cases with significant relation between score of INSM1 and tumor site.

Conclusion: In summary, we confirmed INSM1 expression in a large data set including pituitary adenomas, head and neck NET, lung NET, Mediastinal NET, GI NET, and pancreatic NET, and found high sensitivity for detecting neuroendocrine differentiation as compared with the currently established markers.

Key Words: Insulinoma - Neuroendocrine tumors - Synaptophysin-Chromogranin.

Correspondence to: Dr. Dalia Abd El-Kareem, The Department of Pathology, Faculty of Medicine, Cairo University

\section{Introduction}

DIAGNOSIS of neuroendocrine differentiation is important for tumor classification in different body systems. Confirmation of neuroendocrine differentiation, sometimes require immunohistochemistry (IHC) where morphology is not enough [1]

In some cases, patients with neuroendocrine tumors (NETs) present with metastatic disease as first presentation, therefore the diagnosis is often performed on a small biopsy or cytological sample [2-4]. However, this may be a challenge in the differential diagnosis due to scant tumor cells, crushing artifacts, and/or the presence of necrosis. Conventional immunohistochemical NE markers Chromogranin A, synaptophysin, and CD56 (CGA, SYP, and CD56) are used as complementary tools for the diagnosis of NETs, however sometimes all of them are negative and the diagnosis could still be a challenge [2,5-9] .

Despite the important role played by immunohistochemistry as the primary means of identifying NE differentiation, the utility of the traditional NE markers synaptophysin, chromogranin, and CD56 can sometimes be limited due to few factors: First, the individual and combined sensitivities of these markers is only $50 \%$ to $80 \%$ for high-grade NE tumors [10-14].

Second, CGA, SYP, and CD56 can also be expressed in a wide range of non-NE tumors, including carcinomas, sarcomas, and melanoma [15-26]

Third, the uncertainty of cytoplasmic staining can lead to equivocal results in cases with weak or focal positivity [15-26]

Because of these limitations, there is a great need for a NE marker that is sensitive, specific, and exhibits nuclear expression with a biologic link to the activation of NE differentiation [27]. 
In this regard, different studies were performed on insulinoma-associated protein 1 (INSM1) as a novel and helpful immunohistochemical marker for neuroendocrine neoplasms, and found higher sensitivity and specificity as compared with the established markers $[28,29]$.

Insulinoma-associated protein 1 (INSM1) is a transcription factor that has recently emerged as a helpful diagnostic marker of NE differentiation. INSM1 expression has been tightly linked to NE differentiation in normal and neoplastic tissues in different anatomic sites including the pancreas, gastrointestinal tract, lung, central nervous system, and peripheral nervous system [28-34]

Also, INSM1 plays a vital role in the development of normal neuroendocrine cells throughout the body. It is a zinc-finger transcription factor that was originally isolated from pancreatic insulinomas [10].

Therefore, we performed immunohistochemical study of INSM1, synaptophysin, and chromogranin $\mathrm{A}$, in a comprehensive cohort of 102 different NE tumors, and compared the sensitivity and specificity of these markers.

\section{Material and Methods}

The current study is carried out on 102 cases of neuroendocrine tumors paraffin blocks that were collected from Pathology Department, Faculty of Medicine, Cairo University \& private labs between January 2016 \& January 2020 . The cases included different grades of neuroendocrine tumors from different sites in the human body ( 8 pancreatic NET, 36 cases from gastrointestinal tract, 34 cases from lung, 2 Head \& neck cases, 1 mediastinal cases, and 21 pituitary adenoma).

In all included cases another neuroendocrine marker (synaptophysin and/or chromogranin A) was done for confirmation of diagnosis \& Ki-67 was also done for grading of GIT, pancreas, head $\&$ neck, mediastinal \& lung neuroendocrine tumors according to the latest WHO grading system for neuroendocrine tumors.

Data collected from the sheets included; age, sex, site of the tumor, if there any metastatic deposits, immunohistochemical confirmatory marker \& Ki-labelling index percentage.

Any cases with missing data were excluded from the study.

\section{Immunohistochemical staining procedure:}

For immunohistochemical staining; formalin fixed paraffin-embedded sections of 4 microns thickness were cut on positively charged glass slides, deparaffinized in xylene, then the sections were hydrated through a series of graded alcohols, distilled water \& phosphate buffered saline. Hydrogen peroxide $3 \%$ was used for peroxidase blocking. Antigen retrieval was done using pressure cooker at $121 \mathrm{C}$ for 15 minutes with citrate buffer.

Immunohistochemical staining was performed using INSM1 mouse monoclonal antibody, (Bio $\mathrm{SB}, \mathrm{CA}, \mathrm{USA})$, clone BSB-123, isotype $\mathrm{IgG} 1 / \mathrm{k}$, dilution 1:25 at room temperature according to the standard procedures on automated Ventana immunostainer. After washing in phosphate buffered saline, the samples were incubated with a biotin conjucated secondary antibody and the Ultra view universal DAB-Ventana was used as the detection system.

Counter staining was done using hematoxylin, washed in tap water, placed in 2 changes of $95 \%$ ethyl alcohol then 2 changes of absolute alcohol. Finally, the slides were dried, and cover slips were fixed by DPX (a mixture of distyrene, plasticizer \& xylene).

The present colonic, gastric or bronchial mucosa were used as an internal positive control for INSM1.

\section{Assessment of Insulinoma marker staining:}

Tissue sections were examined under the microscope for the presence of nuclear (brown) staining of INSM1. The percentage of positive tumor cells was calculated as follow: No stained tumor cells $=0$, less than $10 \%$ of tumor cells stained positive $=1+$, from $10 \%$ to $24 \%=2+$, from $25 \%$ to $49 \%=3+$, and $50 \%$ or more $=4+$. Any staining intensity is considered positive [35]

The results of immunostaining were correlated with the clinico-pathological data available.

\section{Statistical analysis:}

- Microsoft excel 2016 was used for data entry and the statistical package for social science (SPSS) version 24 (SPSS, Armonk, New York: International Business Machines Corporation) was used for data analysis.

- Simple descriptive statistics (arithmetic mean and standard deviation) used for summary of quantitative data and frequencies used for qualitative data.

- Bivariate relationship was displayed in cross tabulations and comparison of proportions was performed using the chi-square test or fisher exact whenever appropriate. 
- T-independent, one-way Annova and post-hook tests were used to compare normally distributed quantitative data.

- Pearson correlation was used to compare normally distributed quantitative data.

- The level of significance was set at probability $(p)$ value $<0.05$.

\section{Microscopic photos:}

Microscopic photos were captured using a digital camera attached to Olympus microscope model BX 51.

\section{Results}

One hundred and two cases previously diagnosed as neuroendocrine neoplasm were included in the current study 53 cases $(52 \%)$ were males and 49 cases ( $48 \%$ ) were females, with a male to female ratio is $1.08: 1$. Their ages ranged from 3 to 76 years, with mean age of 46.53 years 15.93 \pm SD. The most common site for the primary tumor was GIT (44\%) followed by lung (42\%) (Fig. 1). The most prevalent tumor type was neuroendocrine tumor grade I $34.3 \%$, While the least was Merkel cell carcinoma 1\% (Fig. 2). Fourteen cases $13.7 \%$ presented with metastasis.

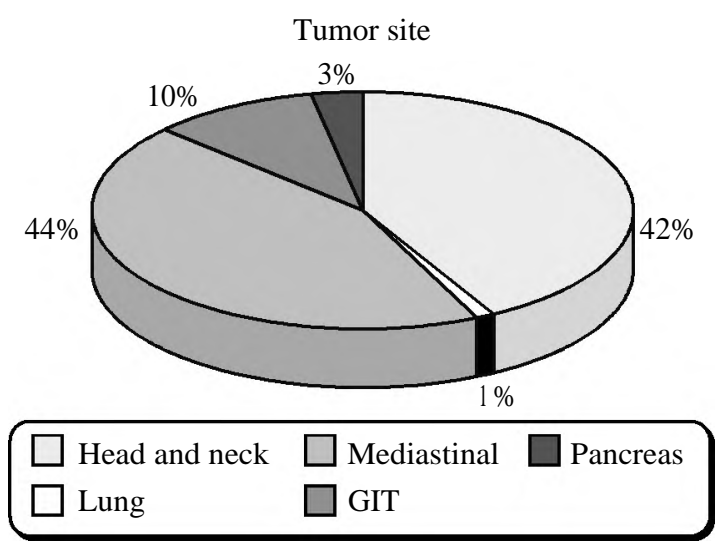

Fig. (1): Distribution of the studied cases according to site.

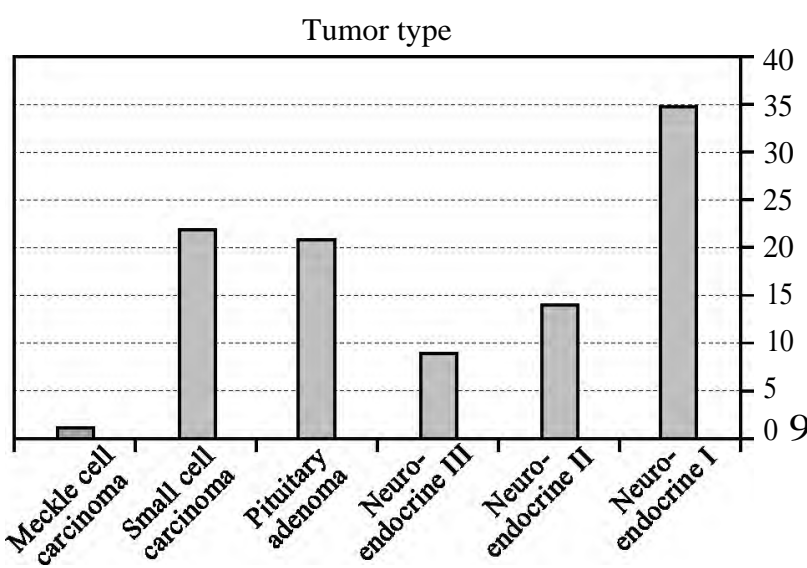

Fig. (2): Histological types of the studied cases.
Positive nuclear expression of INSM1 was detected in 90 cases $88 \%$. $41.2 \%$ score $1,40.2 \%$ score 2, 6.9\% score 3. Negative expression was detected in the remaining 12 cases. No statistical significant relation between positive expressions of INSM1 with the clinicopathological data (Table 1). There was a statistically significant relation between score of INSM1 and tumor site (Pituitary, head and neck, lung, mediastinal, GIT, and pancreas), where most of score 3 staining revealed to be lung NETs 5 (71.4\%) (Table 2).

Table (1): Relation between INSM1 and clinicopathological data.

\begin{tabular}{|c|c|c|c|c|c|}
\hline & \multicolumn{4}{|c|}{ INSM 1} & \multirow{3}{*}{$\begin{array}{c}p- \\
\text { value }\end{array}$} \\
\hline & \multicolumn{2}{|c|}{ Negative } & \multicolumn{2}{|c|}{ Positive } & \\
\hline & Count & $\%$ & Count & $\%$ & \\
\hline Male & 5 & 41.7 & 48 & 53.3 & 0.447 \\
\hline Female & 7 & 58.3 & 42 & 46.7 & \\
\hline Total & 12 & 100.0 & 90 & 100.0 & \\
\hline Pituitary & 0 & 0.0 & 21 & 23.3 & 0.153 \\
\hline Head and neck & 0 & 0.0 & 2 & 2.2 & \\
\hline Lung & 4 & 33.3 & 30 & 33.3 & \\
\hline Mediastinal & 0 & 0.0 & 1 & 1.1 & \\
\hline GIT & 8 & 66.7 & 28 & 31.1 & \\
\hline Pancreas & 0 & 0.0 & 8 & 8.9 & \\
\hline Total & 12 & 100.0 & 90 & 100.0 & \\
\hline Neuroendocrine I & 7 & 58.3 & 28 & 31.1 & 0.166 \\
\hline Neuroendocrine II & 3 & 25.0 & 11 & 12.2 & \\
\hline Neuroendocrine III & 0 & 0.0 & 9 & 10.0 & \\
\hline Pituitary adenoma & 0 & 0.0 & 21 & 23.3 & \\
\hline Small cell carcinoma & 2 & 16.7 & 20 & 22.2 & \\
\hline Merkel cell carcinoma & 0 & 0.0 & 1 & 1.1 & \\
\hline Total & 12 & 100.0 & 90 & 100.0 & \\
\hline No & 11 & 91.7 & 77 & 85.6 & 0.563 \\
\hline Yes & 1 & 8.3 & 13 & 14.4 & \\
\hline Total & 12 & 100.0 & 90 & 100.0 & \\
\hline
\end{tabular}

The sensitivity, specificity, PPV, NPV for INSM1 versus Synaptophysin are 91.1\%, 33.3\%, 91.1\%, 33.3\% respectively. Accuracy $=84.3 \%$.

The sensitivity, specificity, PPV, NPV for INSM1 versus chromogranin are $92.3 \%, 45.5 \%$, $93.3 \%, 41.7 \%$ respectively, accuracy $=87.3 \%$. 
Table (2): Relation between INSM1 score and clinicopathological data

\begin{tabular}{|c|c|c|c|c|c|c|c|c|c|}
\hline & \multicolumn{8}{|c|}{ INSM1 SCORE } & \multirow{3}{*}{$\begin{array}{c}p- \\
\text { value }\end{array}$} \\
\hline & \multicolumn{2}{|c|}{0} & \multicolumn{2}{|c|}{1} & \multicolumn{2}{|c|}{2} & \multicolumn{2}{|c|}{3} & \\
\hline & Count & $\%$ & Count & $\%$ & Count & $\%$ & Count & $\%$ & \\
\hline \multicolumn{10}{|l|}{ Sex: } \\
\hline Male & 5 & 41.7 & 21 & 50.0 & 22 & 53.7 & 5 & 71.4 & \multirow[t]{2}{*}{0.640} \\
\hline Female & 7 & 58.3 & 21 & 50.0 & 19 & 46.3 & 2 & 28.6 & \\
\hline Total & 12 & 100.0 & 42 & 100.0 & 41 & 100.0 & 7 & 100.0 & \\
\hline \multicolumn{10}{|l|}{ Site: } \\
\hline Pituitary & 0 & 0.0 & 13 & 31.0 & 8 & 19.5 & 0 & 0.0 & \multirow[t]{6}{*}{0.010} \\
\hline Head and neck & 0 & 0.0 & 1 & 2.4 & 1 & 2.4 & 0 & 0.0 & \\
\hline Lung & 4 & 33.3 & 12 & 28.6 & 13 & 31.7 & 5 & 71.4 & \\
\hline Mediastinal & 0 & 0.0 & 0 & 0.0 & 0 & 0.0 & 1 & 14.3 & \\
\hline GIT & 8 & 66.7 & 13 & 31.0 & 14 & 34.1 & 1 & 14.3 & \\
\hline Pancreas & 0 & 0.0 & 3 & 7.1 & 5 & 12.2 & 0 & 0.0 & \\
\hline Total & 12 & 100.0 & 42 & 100.0 & 41 & 100.0 & 7 & 100.0 & \\
\hline \multicolumn{10}{|l|}{ Pathology: } \\
\hline Neuroendocrine I & 7 & 58.3 & 13 & 31.0 & 15 & 36.6 & 0 & 0.0 & \multirow[t]{6}{*}{0.057} \\
\hline Neuroendocrine II & 3 & 25.0 & 4 & 9.5 & 6 & 14.6 & 1 & 14.3 & \\
\hline Neuroendocrine III & 0 & 0.0 & 3 & 7.1 & 5 & 12.2 & 1 & 14.3 & \\
\hline Pituitary adenoma & 0 & 0.0 & 13 & 31.0 & 8 & 19.5 & 0 & 0.0 & \\
\hline Small cell carcinoma & 2 & 16.7 & 8 & 19.0 & 7 & 17.1 & 5 & 71.4 & \\
\hline Merkel cell carcinoma & 0 & 0.0 & 1 & 2.4 & 0 & 0.0 & 0 & 0.0 & \\
\hline Total & 12 & 100.0 & 42 & 100.0 & 41 & 100.0 & 7 & 100.0 & \\
\hline \multicolumn{10}{|l|}{ Metastasis: } \\
\hline No & 11 & 91.7 & 39 & 92.9 & 33 & 80.5 & 5 & 71.4 & \multirow[t]{2}{*}{0.231} \\
\hline Yes & 1 & 8.3 & 3 & 7.1 & 8 & 19.5 & 2 & 28.6 & \\
\hline Total & 12 & 100.0 & 42 & 100.0 & 41 & 100.0 & 7 & 100.0 & \\
\hline
\end{tabular}

Fig. (3): (A) small cell carcinoma lung showing positive nuclear staining of INSM1 in about $40 \%$ of tumor cells score $3+$ (immunohistochemistry, X400 original magnification); (B) Appendicular neuroendocrine tumor GI, showing positive nuclear staining of INSM1 in about $20 \%$ of tumor cells score $2+$ (immunohistochemistry, X400 original magnification), (C) Colonic neuroendocrine tumor G I showing positive nuclear staining for INSM1 in less than $10 \%$ of tumor cells score +1 (immunohistochemistry, X400 original magnification), (D) Gastric neuroendocrine tumor GI showing negative staining for INSM1 (immunohistochemistry, $\mathrm{x} 400$ original magnification).
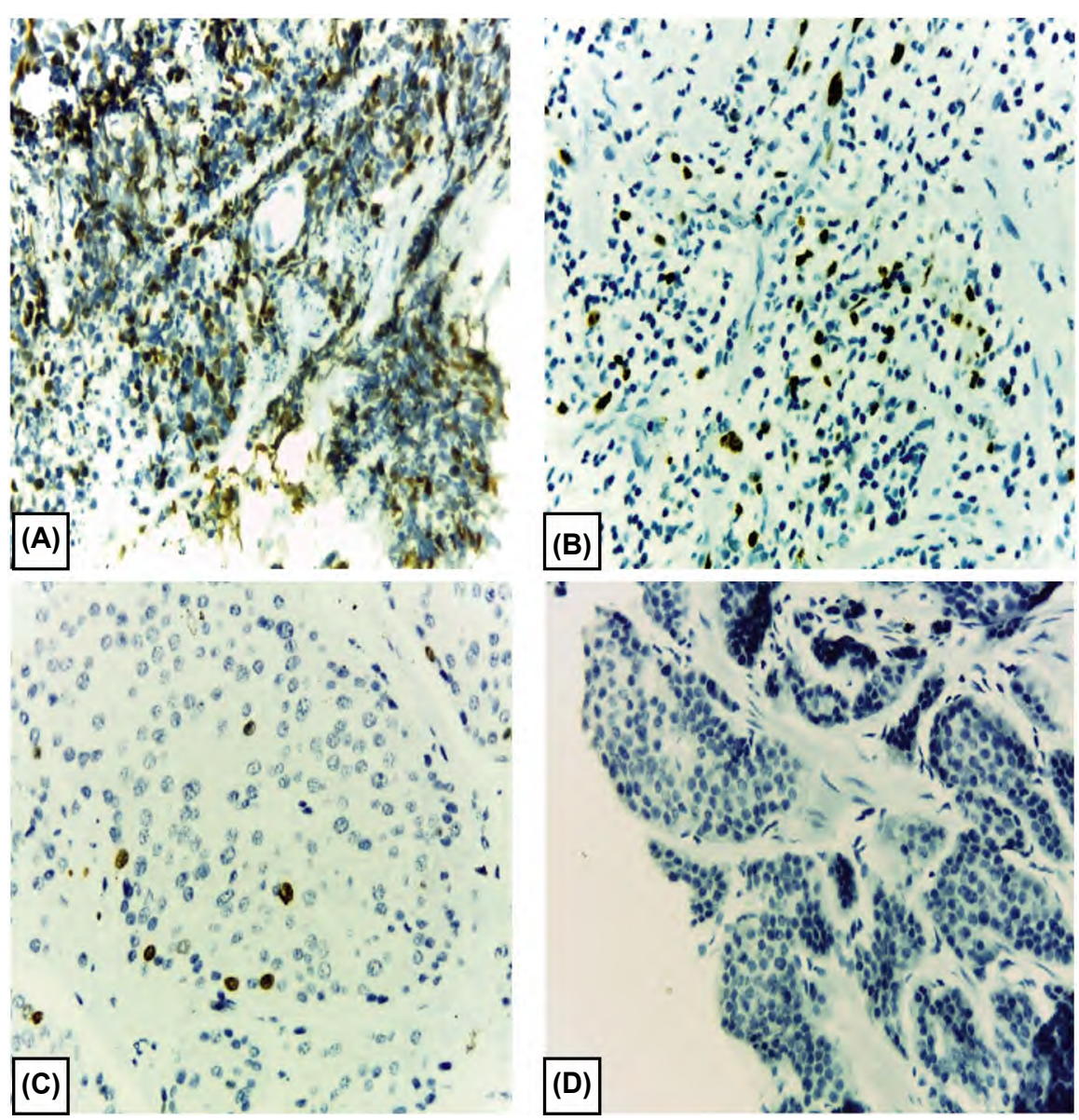


\section{Discussion}

The current study demonstrated 102 cases as 21 pituitary adenomas, 2 head and neck NETs, 34 lung NETs, 1 Mediastinal NETs, 36 GI NETs, and 8 pancreatic NETs.

Out of 36 GI NETs 28 stained positive for INSM1 (77.7\%), 30/34 cases of lung NET stained positive for INSM1 $(88.2 \%), 21 / 21$ pituitary adenomas $(100 \%)$ were positive, all head and neck NET 2/2 (100\%) were positive, all pancreatic NET $8 / 8(100 \%)$ were positive, and the only mediastinal NET case stained positive for INSM1.

Similarly, the study of Fujino K. et al., 2017, reported 7/7 pituitary adenomas stained positive for INSM1, 7/7 merkel cell carcinoma were positive, 13/13 pancreatic NETs were positive, 31/31 GI NETs were positive, 28/28 lung NETs were positive [36].

Our study proved that INSM1 positivity was $31.1 \%$ in NET grade I, $12.2 \%$ in NET grade II, and $10 \%$ in grade III NETs.

Twenty out of 22 SCLC cases $(90.9 \%)$ were positive for INSM1, in concordance with Rooper et al., 2017 who stated that INSM1 was positive in 37 of 39 (94.9\%) SCLCs [27].

The key finding of this study is that INSM1 appears greatly superior to other conventional NE markers (chromogranin A and synaptophysin), and these findings are typically stated by Fujino K. et al. 2017. They demonstrated that INSM1 expression is strong in various NETs and that the reactivity and intensity for INSM1 were considerably high and strong [36].

In our study, the sensitivity, specificity, PPV, NPV for INSM1 versus Synaptophysin were $91.1 \%$, $33.3 \%, 91.1 \%, 33.3 \%$ respectively, with an accuracy of $84.3 \%$, and the same variables were as $92.3 \%, 45.5 \%, 93.3 \%, 41.7 \%$ respectively, when compared to chromogranin A, with an accuracy of $87.3 \%$.

As per Fujino K. et al., 2017 consistently, INSM1 had strong and diffuse reactivity in all NETs except pheochromocytomas, the mean reactivity of INSM1/CGA/SYP/CD56 in NETs was $85 \% / 66 \% / 84 \% / 64 \%$. The mean H-score was superior or more than equivalent in the majority of NETs (INSM1/CGA/SYP/CD56, 211/ 122/191/117, $\mathrm{P} p<0.0001)[36]$.

Fujino K. et al., 2015 also reported that INSM1 is a superior immunohistochemical diagnostic marker for SCLC compare to NE markers (CGA, SYP, and CD56) used in the clinical pathological diagnosis field [29]. Also, Rosenbaum et al., 2015 examined 129 neuroendocrine neoplasm specimens and found that INSM1 was positive in $88.3 \%$ of cases using IHC staining [37]. Parallel to the current study, these two studies presented the highlyspecificity of INSM1 compared with the other NE markers.

Also, the study of Tanigawa, M. et al., 2018 compared the sensitivity of INSM1 in NET that was significantly higher compared with that of NCAM staining and higher than that of CGA. In contrast, there were no statistically significant differences found in SYP [38].

INSM1 specificity in pancreatic solid tumors was high in Solid pseudopapillary neoplasm, there was a significant difference with NCAM, and there was no expression of INSM1 in any of the Acinar cell carcinoma or pancreatic ductal adenocarcinoma cases. In SYP, there were no significant differences seen in INSM1 and specificity [38]

The two cases of head and neck NETs in our study revealed positive staining for INSM1. The results of Rooper et al., 2018 demonstrated that INSM1 is a highly sensitive diagnostic marker for identification of NE differentiation in the head and neck [25] proving that NE differentiation has relied on a panel approach due to the limited sensitivity and equivocal staining patterns of synaptophysin, chromogranin, and CD56 [10-14] . Not only INSM1 is found to be superior to the individual and combined performance of these traditional NE markers with a $99.0 \%$ overall sensitivity in a comprehensive cohort of 97 head and neck NE tumors in this series, but it also shows a higher (95.8\%) sensitivity for high-grade NE malignancies such as small cell carcinoma, large cell NE carcinoma, and sinonasal teratocarcinosarcoma.

Furthermore, INSM 1 demonstrates a quantitatively equivalent degree of staining to synaptophysin, chromogranin, and CD56 but with intense nuclear signals that are easier for interpretation as positive or negative than the granular cytoplasmic staining of the traditional markers [10-14].

INSM1 might be a strong additional marker for neuroendocrine differentiation and we fully agree with the previous studies judgement that nuclear staining was easier to interpret compared with the cytoplasmic or membranous staining of the established markers that sometimes may be focal or weak. 
Besides, its role as a diagnostic biomarker, INSM1 may have a good prognostic biomarker with a predictive potential that has been suggested in previous studies, a finding that awaits confirmation and more investigations [28]

In summary, we confirmed INSM1 expression in a large data set including pituitary adenomas, head and neck NET, lung NET, Mediastinal NET, GI NET, and pancreatic NET, and found high sensitivity for detecting neuroendocrine differentiation as compared with the currently established markers.

A study in comparison with expression of INSM 1 in other non-NETs is also needed for confirmatory purposes.

\section{References}

1- INAMURA K.: Update on immunohistochemistry for the diagnosis of lung cancer. Cancers, 10 (3): p.72, 2018.

2- WOOD D.E.: National Comprehensive Cancer Network (NCCN) clinical practice guidelines for lung cancer screening. Thoracic Surgery Clinics, 25 (2): pp.185-197, 2015.

3- WASHINGTON M.K., TANG L.H., BERLIN J., BRANTON P.A., BURGART L.J., CARTER D.K., COMPTON C.C., FITZGIBBONS P.L., FRANKEL W.L., JESSUP J.M. and KAKAR S.: Protocol for the examination of specimens from patients with neuroendocrine tumors (carcinoid tumors) of the colon and rectum. Archives of pathology \& laboratory medicine, 134 (2): pp.176-180, 2010.

4- TANG L.H., BASTURK O., SUE J.J. and KLIMSTRA D. S.: A practical approach to the classification of WHO grade 3 (G3) well differentiated neuroendocrine tumor (WD-NET) and poorly differentiated neuroendocrine carcinoma (PD-NEC) of the pancreas. The American Journal of Surgical Pathology, 40 (9): p.1192, 2016.

5- HELPAP B. and KÖLLERMANN J.: Immunohistochemical analysis of the proliferative activity of neuroendocrine tumors from various organs. Virchows Archiv, 438 (1): pp.86-91, 2001.

6- KUNZ P.L.: Carcinoid and neuroendocrine tumors: Building on success. Journal of Clinical Oncology, 33 (16): pp.1855-1863, 2015.

7- REKHTMAN N.: Neuroendocrine tumors of the lung: An update. Archives of Pathology and Laboratory Medicine, 134 (11): pp.1628-1638, 2010.

8- GUT P., CZARNYWOJTEK A., FISCHBACH J., BACZYK M., ZIEMNICKA K., WROTKOWSKA E., GRYCZYN'SKA M. and RUCHAL'A M.: Chromogranin Aunspecific neuroendocrine marker. Clinical utility and potential diagnostic pitfalls. Archives of Medical Science: AMS, 12 (1): p.1, 2016.

9- MODLIN I.M., OBERG K., TAYLOR A., DROZDOV I., BODEI L. and KIDD M.: Neuroendocrine tumor biomarkers: Current status and perspectives. Neuroendocrinology, 100 (4): pp.265-277, 2014.
10- FERLITO, A. and FRIEDMANN I.: Contribution of immunohistochemistry in the diagnosis of neuroendocrine neoplasms of the larynx. ORL, 53 (4): pp.235-244, 1991.

11- NELSON R.S., PERLMAN E.J. and ASKIN F.B.: Is esthesioneuroblastoma a peripheral neuroectodermal tumor?. Human Pathology, 26 (6): pp.639-641, 1995.

12- RINALDO A., DEVANEY K.O. and FERLITO A.: Immunohistochemical studies in support of a diagnosis of small cell neuroendocrine carcinoma of the larynx. Acta oto-laryngologica, 124 (5): pp.638-641, 2004.

13- SERRANO M.F., EL-MOFTY S.K., GNEPP D.R. and LEWIS Jr., J.S.:Utility of high molecular weight cytokeratins, but not p63, in the differential diagnosis of neuroendocrine and basaloid carcinomas of the head and neck. Human Pathology, 39 (4): pp.591-598, 2008.

14- SOUSSI A.C., BENGHIAT A., HOLGATE C.S. and MAJUMDAR B.: Neuro-endocrine tumours of the head and neck. The Journal of Laryngology \& Otology, 104 (6): pp.504-507, 1990.

15- BAHRAMI A., GOWN A.M., BAIRD G.S., HICKS M.J. and FOLPE, A.L.: Aberrant expression of epithelial and neuroendocrine markers in alveolar rhabdomyosarcoma: A potentially serious diagnostic pitfall. Modern Pathology, 21 (7): pp.795-806, 2008.

16- LEE H., TORRES F.X., McLEAN S.A., CHEN R. and LEE M.W.: Immunophenotypic heterogeneity of primary sinonasal melanoma with aberrant expression of neuroendocrine markers and calponin. Applied Immunohistochemistry \& Molecular Morphology, 19 (1): pp.48-53, 2011.

17- SATOH F., UMEMURA S., YASUDA M. and OSAMURA R.Y.: Neuroendocrine marker expression in thyroid epithelial tumors. Endocrine Pathology, 12 (3): pp.291-299, 2001.

18- SCHARTINGER V.H., FALKEIS C., LAIMER K., SPRINZL G.M., RIECHELMANN H., RASSE M., VIRGOLINI I. and DUDÁS J.: Neuroendocrine differentiation in head and neck squamous cell carcinoma. The Journal of Laryngology and Otology, 126 (12): p.1261, 2012.

19- THOMPSON L.D., JO V.Y., AGAIMY A., LLOMBARTBOSCH A., MORALES G.N., MACHADO I., FLUCKE U., WAKELY P.E., MIETTINEN M. and BISHOP J.A.: Sinonasal tract alveolar rhabdomyosarcoma in adults: A clinicopathologic and immunophenotypic study of fiftytwo cases with emphasis on epithelial immunoreactivity. Head and Neck Pathology, 12 (2): pp.181-192, 2018.

20- BISHOP J.A., ALAGGIO R., ZHANG L., SEETHALA R.R. and ANTONESCU, C.R.: Adamantinoma-like Ewing family tumors of the head and neck: A pitfall in the differential diagnosis of basaloid and myoepithelial carcinomas. The American Journal of Surgical Pathology, 39 (9): p.1267, 2015

21- BISHOP J.A., ANTONESCU C.R. and WESTRA W.H.: SMARCB1 (INI-1) deficient carcinomas of the sinonasal tract. The American Journal of Surgical Pathology, 38 (9): p.1282, 2014.

22- AGAIMY A., HARTMANN A., ANTONESCU C.R., CHIOSEA S.I., EL-MOFTY S.K., GEDDERT H., IRO H., LEWIS JR., J.S., MÄRKL, B., MILLS S.E. and RIENER M.O.: SMARCB1 (INI-1)-deficient sinonasal carcinoma: a series of 39 cases expanding the morphological and clinicopathological spectrum of a recently described 
entity. The American Journal of Surgical Pathology, 41 (4): p.458, 2017.

23- KHAN A., TISCHLER A.S., PATWARDHAN N.A. and DELELLIS R.A.: Calcitonin immunoreactivity in neoplastic and hyperplastic parathyroid glands: An immunohistochemical study. Endocrine Pathology, 14 (3): pp.249$255,2003$.

24- TOMITA T.: Immunocytochemical staining patterns for parathyroid hormone and chromogranin in parathyroid hyperplasia, adenoma, and carcinoma. Endocrine Pathology, 10 (2): pp. 145-156, 1999.

25- ROOPER L.M., BISHOP J.A. and WESTRA W.H.: INSM1 is a sensitive and specific marker of neuroendocrine differentiation in head and neck tumors. The American Journal of Surgical Pathology, 42 (5): pp.665-671, 2018.

26- DOXTADER E.E. and MUKHOPADHYAY S.: Insulinoma-associated protein 1 is a sensitive and specific marker of neuroendocrine lung neoplasms in cytology specimens. Cancer Cytopathology, 126 (4): pp.243-252, 2018

27- ROOPER L.M., SHARMA R., LI Q.K., ILLEI P.B. and WESTRA, W.H.: INSM1 demonstrates superior performance to the individual and combined use of synaptophysin, chromogranin and CD56 for diagnosing neuroendocrine tumors of the thoracic cavity. The American Journal of Surgical Pathology, 41 (11): pp.1561-1569, 2017.

28- BRESLIN M.B., ZHU M., NOTKINS A.L. and LAN M.S.: Neuroendocrine differentiation factor, IA-1, is a transcriptional repressor and contains a specific DNAbinding domain: identification of consensus IA-1 binding sequence. Nucleic Acids Research, 30 (4): pp. 1038-1045, 2002.

29- FUJINO K., MOTOOKA Y., HASSAN W.A., ABDALLA M.O.A., SATO Y., KUDOH S., HASEGAWA K., NIIMORI-KITA K., KOBAYASHI H., KUBOTA I. and WAKIMOTO J.: Insulinoma-associated protein 1 is a crucial regulator of neuroendocrine differentiation in lung cancer. The American Journal of Pathology, 185 (12): pp.3164-3177, 2015.

30- GIERL M.S., KAROULIAS N., WENDE H., STREHLE M. and BIRCHMEIER C.: The zinc-finger factor Insm1 (IA-1) is essential for the development of pancreatic P cells and intestinal endocrine cells. Genes \& development, 20 (17): pp.2465-2478, 2006.
31- GOTO Y., De SILVA M.G., TOSCANI A., PRABHAKAR B.S., NOTKINS A.L. and LAN M.S.: A novel human insulinoma-associated cDNA, IA-1, encodes a protein with" zinc-finger" DNA-binding motifs. Journal of Biological Chemistry, 267 (21): pp.15252-15257, 1992.

32- LAN M.S. and BRESLIN M.B.: Structure, expression, and biological function of INSM1 transcription factor in neuroendocrine differentiation. The FASEB Journal, 23 (7): pp.2024-2033, 2009.

33- LAN M.S., RUSSELL E.K., LU J., JOHNSON B.E. and NOTKINS A.L.: IA-1, a new marker for neuroendocrine differentiation in human lung cancer cell lines. Cancer Research, 53 (18): pp.4169-4171, 1993.

34- TANIWAKI M., DAIGO Y., ISHIKAWA N., TAKANO A., TSUNODA T., YASUI W., INAI K., KOHNO N. and NAKAMURA Y.: Gene expression profiles of small-cell lung cancers: Molecular signatures of lung cancer. International Journal of Oncology, 29 (3): pp.567-575, 2006.

35- STAAF J., TRAN L., SÖDERLUND L., NODIN B., JIRSTRÖM K., VIDARSDOTTIR H., PLANCK M. MATTSSON J.S., BOTLING J., MICKE P. and BRUNNSTRÖM H.: Diagnostic Value of InsulinomaAssociated Protein 1 (INSM1) and Comparison With Established Neuroendocrine Markers in Pulmonary Cancers: A Comprehensive Study and Review of the Literature. Archives of Pathology \& Laboratory Medicine, 2020.

36- FUJINO K., YASUFUKU K., KUDOH S., MOTOOKA Y., SATO Y., WAKIMOTO J., KUBOTA I., SUZUKI M and ITO T.: INSM1 is the best marker for the diagnosis of neuroendocrine tumors: Comparison with CGA, SYP and CD56. Int. J. Clin. Exp. Pathol, 10 (5): pp.5393-5405, 2017.

37- ROSENBAUM J.N., GUO Z., BAUS R.M., WERNER H., REHRAUER W.M. and LLOYD R.V.: INSM1: A novel immunohistochemical and molecular marker for neuroendocrine and neuroepithelial neoplasms. American Journal of Clinical Pathology, 144 (4): pp.579-591, 2015.

38- TANIGAWA M., NAKAYAMA M., TAIRA T., HATTORI S., MIHARA Y., KONDO R., KUSANO H., NAKAMURA K., ABE Y., ISHIDA Y. and OKABE Y.: Insulinomaassociated protein 1 (INSM1) is a useful marker for pancreatic neuroendocrine tumor. Medical Molecular Morphology, 51 (1): pp.32-40, 2018. 


\section{البروتين المرتبط بالورم الأنسولينى رقم ا كعلامة مناعية جديدة للأورام الهرمونية العصبية ونمبية}

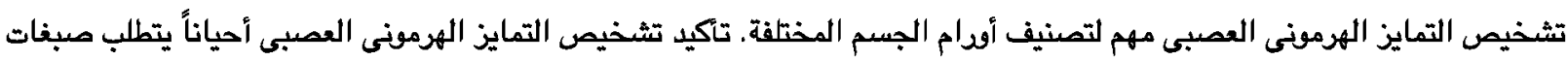

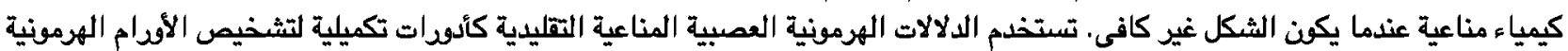

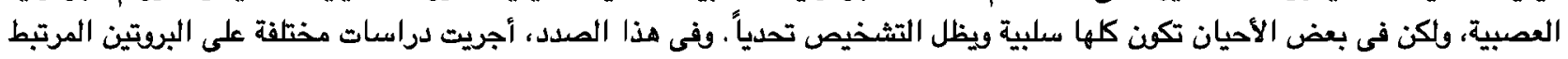

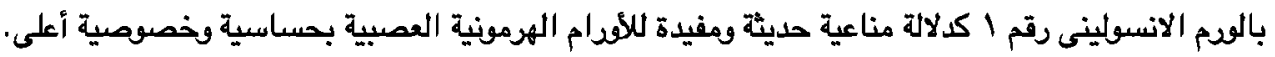

تهدف هذه الدراسة إلى إثبات أهمية البروتين المرتبط بالوم الانسولينى رقم المدلالة مناعية حديثة للأورام الهرمونية العصبية وإثبات

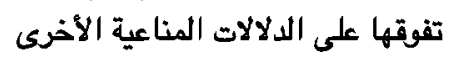

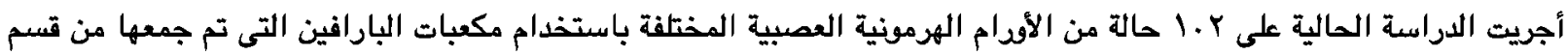

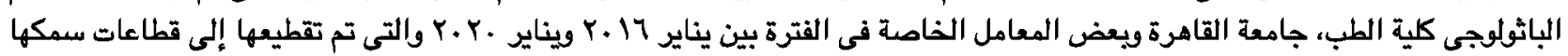

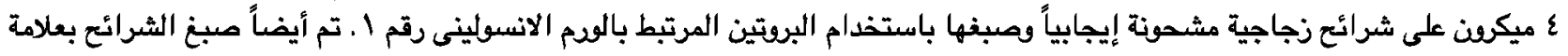

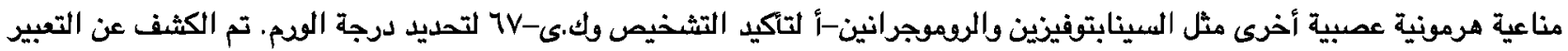

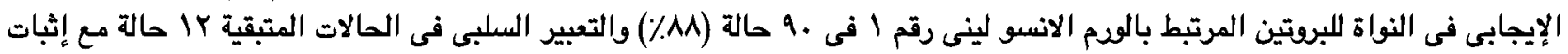

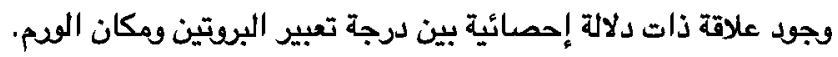

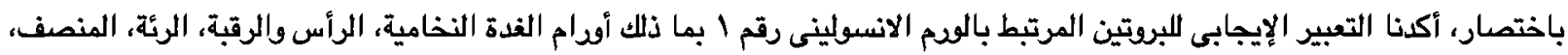

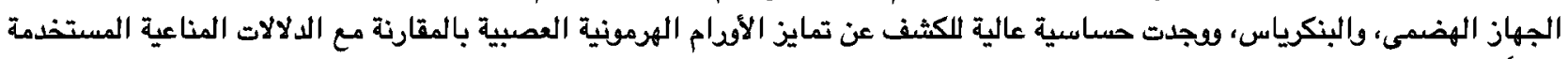

